\title{
Model Challenge Based Learning terhadap Kemampuan Berpikir Kreatif Mahasiswa
}

\author{
Suratman S. Naim ${ }^{1}$, Suhadi Ibnu ${ }^{1}$, Aman Santoso ${ }^{1}$ \\ ${ }^{1}$ Pendidikan Kimia-Universitas Negeri Malang
}

\begin{tabular}{l} 
INFO ARTIKEL \\
\hline Riwayat Artikel: \\
Diterima: 04-12-2019 \\
Disetujui: 16-04-2020 \\
\hline
\end{tabular}

\section{Kata kunci:}

challenge based learning; creative thinking skills; chemical environment; challenge based learning; kemampuan berpikir kreatif; kimia lingkungan

\author{
Alamat Korespondensi: \\ Suratman S. Naim \\ Pendidikan Kimia \\ Universitas Negeri Malang \\ Jalan Semarang 5 Malang \\ E-mail: naimsuratman@gmail.com
}

\begin{abstract}
ABSTRAK
Abstract: The purpose of this research was to determine the influence of challenge based learning model on students creative thinking ability. This research is used a quasy-experimental design of the type nonequivalent pretest-posttest control group design. The sample of this research consisted of students of Chemistry Education, Khairun University in the sixth semester, enrolling in the subject of Environmental Chemistry during education year in 2018/2019 from two classes. The experimental class was taught with challenge based learning model and the control class was taught with problem based learning model. The instrument of the research was a creative thinking ability tests with the type of open essay questions that had validity of $77.08 \%$ and Alpha Cronbach reliability coefficient of 0.896 . The results showed that there was no statistically significant difference in creative thinking ability between the students from the two research classes $(a=0.05)$, although descriptively the creative thinking ability of the experimental class was better than the control class.
\end{abstract}

\begin{abstract}
Abstrak: Tujuan penelitian ini adalah untuk mengetahui pengaruh model challenge based learning terhadap kemamampuan berpikir kreatif mahasiswa. Penelitian ini menggunakan rancangan penelitian eksperimental semu tipe nonequivalent pretestposttest control group design. Sampel penelitian ini terdiri dari mahasiswa Pendidikan Kimia, Universitas Khairun angkatan 2016 yang menempuh matakuliah Kimia Lingkungan pada tahun ajaran 2018/2019 dari dua kelas. Kelas eksperimen dibelajarkan dengan model pembelajaran challenge based learning dan kelas kontrol dibelajarkan dengan model pembelajaran problem based learning. Instrumen penelitian adalah tes kemampuan berpikir kreatif dengan jenis soal esai terbuka yang memiliki validitas isi 77,08\% dan koefisien reliabilitas Alpha Cronbach 0,893. Hasil penelitian memperlihatkan bahwa tidak ada perbedaan yang signifikan antara kemampuan berpikir kreatif mahasiswa dari kedua kelas penelitian $(a=0.05)$, walaupun secara deskriptif kemampuan berpikir kreatif kelas eksperimen lebih bagus daripada kelas kontrol.
\end{abstract}

Kimia lingkungan merupakan bidang keilmuan yang membahas fenomena-fenomena kimia yang terjadi di alam akibat aktivitas manusia (Manahan, 2010). Masalah-masalah lingkungan, seperti polusi lingkungan, peningkatan populasi yang cepat, pemanasan global dan perubahan iklim, perusakan vegetasi alam dan sumber daya bumi, berkurangnya area pertanian dan sumber daya air, penghancuran lapisan ozon serta penurunan keanekaragaman hayati (Günter et al, 2017). Masalah lingkungan tersebut dan segala dampak yang timbulkankannya perlu dipahami dengan baik oleh peserta didik, sehingga ada upaya penanggulangan maupun penemuan solusi dari mereka (Günter et al., 2017). Jika masalah lingkungan yang menyangkut prinsip keadilan sosial dan lingkungan dapat dihadirkan dalam pembelajaran kimia, tentu akan memberikan kerangka kerja untuk mengurangi dampak yang ditimbulkan, serta menjadikan peserta didik sebagai generasi paham kimia yang dapat mengupayakan keseimbangan lingkungan di masa depan (Lasker \& Brush, 2019).

Berdasarkan studi literatur, pelaksanaan pembelajaran kimia lingkungan di perguruan tinggi masih memiliki beberapa masalah yang serius. Pembelajaran kimia lingkungan sering dianggap berkonotasi negatif oleh peserta didik karena berbagai pencemaran lingkungan yang disebabkan industri kimia dan penggunaan bahan kimia yang salah (Ryu et al., 2018; Salta et al., 2012). Pembelajaran kimia lingkungan tidak memiliki laboratorium eksperimen yang dirancang khusus untuk mensimulasikan hubungan antara struktur kimia dan perilaku zat di lingkungan (Avellar at al., 2012). Pembelajaran kimia lingkungan cenderung menggunakan strategi pembelajaran; model, metode, dan pendekatan yang memuat disiplin keilmuan sebagai kumpulan topik yang terisolasi dari bidang keilmuan lainnya (Savian \& Talanquer, 2014). Pengajar masih menggunakan metode diskusi pada materi kimia yang bersifat prosedural dan model pembelajaran langsung pada materi kimia yang bersifat faktual. Oleh karena 
itu, mahasiswa tidak mampu merespons masalah-masalah lingkungan yang terjadi saat ini dengan baik karena mahasiswa tidak memiliki kemampuan berpikir. Pembelajaran kimia lingkungan harus berfokus pada proses alami yang bertanggung jawab untuk keseimbangan lingkungan dan memeriksa zat yang digunakan dalam kehidupan kita sehari-hari yang memengaruhi populasi dan lingkungan (Avellar et al., 2012). Pembelajaran kimia lingkungan memerlukan pendekatan multidisiplin untuk menjamin studi lintas dalam kegiatan pembelajaran, dimana kimia sebagai disiplin yang memiliki peran penting (Avellar et al., 2012; Jansson et al., 2015). Pembelajaran kimia lingkungan membutuhkan pendekatan pedagogis yang memberikan banyak momen pengajaran meliputi; tantangan penyelidikan, kuantisasi tingkat rendah dalam sampel lingkungan, serta peluang pengembangan keterampilan kerja kelompok (Davis et al, 2016). Oleh karena itu, pembelajaran kimia lingkungan perlu untuk mencoba strategi baru yang lebih menantang.

Challenge Based Learning (CBL) merupakan model pembelajaran baru yang memuat beberapa karakteristik pembelajaran sebelumnya, terdiri dari pembelajaran berbasis masalah, pembelajaran berbasis proyek, dan pembelajaran konstekstual (Johnson \& Adams, 2011; Johnson, et al., 2009). Model CBL memfokuskan pembelajaran pada penyelesaian tantangan dari masalah kehidupan nyata (L. F. Johnson et al., 2009), menciptakan ruang yang lebih besar bagi peserta didik untuk selalu aktif berkolaborasi (Nichols et al., 2016). Model CBL lebih menekankan pada kemampuan berpikir untuk mengkonstruk pengetahuan baru dari pengalamannya belajarnya (Swiden, 2013). Kemampuan berpikir dan pemecahan masalah dibutuhkan dalam menemukan solusi terhadap tantangan.

Tahapan-tahapan model Challenges Based Learning (CBL), meliputi ide besar, pertanyaan penting, tantangan, pertanyaan pemandu, kegiatan pemandu, sumber pemandu, solusi, penilaian dan publikasi (L. F. Johnson et al., 2009). Pada tahapan-tahapan tersebut mahasiswa dilibatkan berinteraksi secara aktif untuk menemukan, menyelidiki, dan menyelesaikan tantangan yang diberikan oleh pendidik (O’Mahony et al., 2012). Tantangan peserta didik berkaitan dengan masalah kehidupan nyata yang didesain secara menarik untuk kegiatan pembelajaran (Baloian et al., 2004). Tantangan yang menarik diharapkan dapat merangsang motivasi ekstrinsik peserta didik untuk belajar dengan sungguh-sungguh (Jou et al., 2010). Tantangan yang diberikan diharapkan dapat menuntut mahasiswa agar mandiri, kreatif, dan inovatif dalam kegiatan penyelidikan, mahasiswa menemukan tantangannya sendiri, melakukan kegiatan penyelidikan, serta memberikan solusi terhadap tantangan tersebut.

Beberapa hasil penelitian mengungkapkan bahwa model CBL diterapkan pada pembelajaran sains dapat menumbuhkan kemampuan berpikir dan pemecahan masalah mahasiswa di tingkat perguruan tinggi. Model CBL yang dibelajarkan pada mahasiswa keperawatan dapat meningkatkan kreativitas dan efektivitas inovasi (Yang et al., 2018). Model CBL digabungkan dengan blended learning dapat menggali kemampuan berpikir kritis mahasiswa pendidikan biologi (Saefi, Suwono, \& Susilo, 2017). Model CBL berpengaruh baik bagi keterampilan kolaboratif, pemecahan masalah dan kreativitas mahasiswa pendidikan biologi (Fitriani, 2018).

Model Challenge Based Learning (CBL) dapat digunakan dalam pembelajaran kimia lingkungan karena materi-materi kimia lingkungan sangat berhubungan dengan kehidupan mahasiswa (kontekstual). Materi kimia lingkungan dapat didesain menjadi sebuah tantangan yang menarik dalam kegiatan pembelajaran. Pencemaran lingkungan merupakan materi pokok kimia lingkungan yang sangat urgen untuk dipahami dengan baik oleh mahasiswa. Pencemaran lingkungan yang meliputi; pencemaran air, tanah, dan udara sangat relevan dengan model pembelajaran berbaris tantangan karena berkaitan dengan keseharian mahasiswa, serta bermanfaat bagi kehidupan manusia. Pencemaran lingkungan dapat didesain secara menarik dalam bentuk tantangan (challenges). Contoh masalah-masalah pencemaran lingkungan yang dapat diangkat menjadi tantangan, yaitu pencemaran air di sekitar pelabuhan speed boat, pencemaran tanah di akibat erupsi gunung merapi, dan pencemaran udara di sekitar kawasan PLTU. Dengan demikian, model CBL dapat digunakan pada pembelajaran kimia lingkungan untuk menumbuhkan kemampuan berpikir kreatif mahasiswa.

\section{METODE}

Rancangan penelitian ini ialah eksperimental semu tipe nonequivalent pretest-posttest control group design. Pengambilan sampel menggunakan teknik purposive sampling pada mahasiswa Pendidikan Kimia, Universitas Khairun. Diperoleh dua kelas, dimana kelas eksperimen diajarkan menggunkan model challenge based learning berjumlah 18 mahasiswa $(\mathrm{N}=18)$, dan kelas kontrol diajarkan menggunkan model problem based learning berjumlah 18 mahasiswa $(\mathrm{N}=18)$.

Tabel 1. Desain Penelitian

\begin{tabular}{cccc}
\hline Kelas & Prestest & Perlakuaan & Posttest \\
\hline Eksperimen & $\mathrm{O}_{1}$ & $\mathrm{X}_{1}$ & $\mathrm{O}_{3}$ \\
Kontrol & $\mathrm{O}_{2}$ & $\mathrm{X}_{2}$ & $\mathrm{O}_{4}$ \\
\hline
\end{tabular}

(Sumber: Beaumont, 2009)

Keterangan:

$\mathrm{O}_{1}$ : Pretest untuk kelas eksperimen

$\mathrm{O}_{2}$ : Pretest untuk kelas kontrol

$\mathrm{O}_{3}$ : Posttest untuk kelas eksperimen. 
$\mathrm{O}_{4}:$ Posttest untuk kelas kontrol

$\mathrm{X}_{1}$ : Kelas yang dibelajarkan dengan model CBL

$\mathrm{X}_{2}$ : Kelas yang dibelajarkan dengan model PBL

Tes kemampuan berpikir kreatif menggunakan jenis soal essay terbuka. Tes tersebut dibuat berdasarkan indikatorindikator kemampuan berpikir kreatif dari Torrance (Pellegrin et al, 2018). Teknik penskoran tes kemampuan berpikir kreatif dikembangkan dari Munandar (2009).

Tabel 2. Indikator Penyusunan Tes Kemampuan Berpikir Kreatif

\begin{tabular}{|c|c|c|}
\hline No. & Aspek & $\begin{array}{ll}\text { Indikator } \\
\end{array}$ \\
\hline 1. & Fluency & $\begin{array}{l}\text { - Memberikan beberapa gagasan/jawaban terhadap suatu masalah; } \\
\text { - Mengungkapkan gagasan/jawaban dengan lancar; } \\
\text { - Mengungkapkan kekeliriuan dari suatu objek atau situasi. }\end{array}$ \\
\hline 2. & Flexibility & $\begin{array}{l}\text { - Menghasilkan berbagai penafsiran terhadap suatu gambaran, deskripsi, atau masalah; } \\
\text { - Menghasilkan berbagai cara berbeda untuk menyelesaikannya suatu masalah; } \\
\text { - Menggolongkan sesuatu hal berdasarkan pembagian (kategori) yang berbeda. }\end{array}$ \\
\hline 3. & Originality & - Menghasilkan gagasan baru dari gagasan-gagasan yang telah ada sebelumnya terhadap suatu masalah. \\
\hline 4. & Elaboration & $\begin{array}{l}\text { - Menggali arti atau makna terhadap jawaban atau pemecahan masalah melalui langkah-langkah terperinci; } \\
\text { - Mengelaborasi gagasan sebelumnya; } \\
\text { - Menganalisis detail-detail baru untuk melihat baru agar dapat dilalui. }\end{array}$ \\
\hline 5. & Evaluation & $\begin{array}{l}\text { - Menilai jawaban yang paling tepat untuk menyelesaikan sebuah masalah; } \\
\text { - Memberikan masukan yang tepat terhadap gagasan orang lain. }\end{array}$ \\
\hline
\end{tabular}

(Sumber: Torrance dalam Pellegrin et al., 2019)

\section{HASIL}

Hasil didapatkan dari pelaksanaan tes kemampuan berpikir kreatif sebelum dan setelah kegiatan pembelajaran. Hasil tes tersebut dianalisis untuk melihat perbedaan kemampuan berpikir kreatif antara kelas eksperimen yang dibelajarkan dengan model challenge based learning dan kelas kontrol yang dibelajarkan dengan model problem based learning, serta untuk mengetahui selisih antara pretest dan posttest kedua kelas penelitian.

Tabel 3. Skor Rata-Rata Posttest Kemampuan Berpikir Kreatif

\begin{tabular}{ccccc}
\hline No. & Kelas & Jumlah Mahasiswa & Standar Deviasi & Rata-Rata \\
\hline 1. & Eksperimen & 18 & 11,905 & 49,02 \\
2. & Kontrol & 18 & 11,991 & 44,96 \\
\hline
\end{tabular}

Tabel 3 memperlihatkan skor rata-rata posttest kemampuan berpikir kreatif dari kelas eksperimen yang dibelajarkan dengan model CBL sebesar 49,02, sedangkan dari kelas kontrol yang dibelajarkan dengan model PBL sebesar 44,96. Sehingga dapat disimpulkan bahwa skor rata-rata posttest kemampuan berpikir kreatif kelas eksperimen lebih besar dibandingkan kelas kontrol. Gambar 1 memperlihatkan skor rata-rata posttest kemampuan berpikir kreatif kedua penelitian.

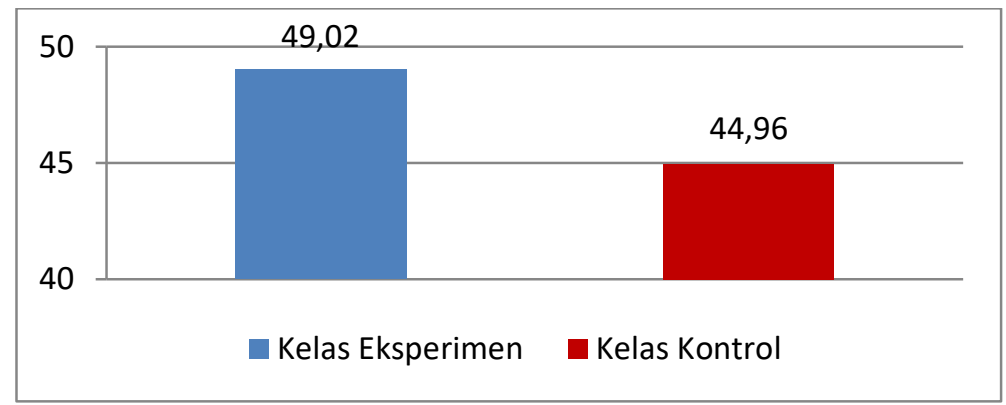

\section{Gambar 1. Skor Rata-Rata Posttest Kemampuan Berpikir Kreatif}

Berdasarkan gambar 1, mahasiswa dari kedua kelas belum menumbuhkan kemampuan berpikir kreatif. Secara kuantitas, mahasiswa belum mencapai skor 50. Perbedaan kemampuan berpikir kreatif mahasiswa antara kelas eksperimen dan kelas kontrol diketahui dengan uji hipotesis. Sebelum diuji hipotesis, dilaksanakan uji prasyarat pada data pretest-posttest terlebih dahulu. 
Tabel 4. Hasil Uji Normalitas

\begin{tabular}{llcccc}
\hline & \multicolumn{3}{c}{ One-Sample Kolmogorov-Smirnov Test } \\
\hline & & \multicolumn{3}{c}{ Pretest } & \multicolumn{2}{c}{ Posttest } \\
\cline { 3 - 6 } & & 18 & 18 & 18 & 18 \\
\hline \multirow{2}{*}{ Kelas Eksperimen } & Kelas Kontrol & Kelas Eksperimen & Kelas Kontrol \\
\hline \multirow{2}{*}{ Normal Parameters ${ }^{\text {a,b }}$} & Mean & 22,92 & 18,06 & 49,02 & 44,96 \\
& Std. Deviation & 11,443 & 10,640 & 11,905 & 11,991 \\
\hline \multirow{2}{*}{ Most Extreme Differences } & Absolute & 0,206 & 0,199 & 0,134 & 0,207 \\
& Positive & 0,206 & 0,199 & 0,134 & 0,207 \\
& Negative & $-0,161$ & $-0,134$ & $-0,107$ & $-0,133$ \\
\hline Kolmogorov-Smirnov Z & & 0,872 & 0,845 & 0,568 & 0,878 \\
Asymp. Sig. (2-tailed) & & 0,433 & 0,473 & 0,904 & 0,424 \\
\hline
\end{tabular}

Tabel 4 menggambarkan bahwa data pretest kemampuan berpikir kreatif kelas eksperimen memiliki angka Sig. $(0,872)>0,05$, sedangkan data pretest kemampuan berpikir kreatif kelas kontol memiliki angka Asymp. Sig. $(0,845)>0,05$. Selain itu, data posttest kemampuan berpikir kreatif kelas eksperimen memiliki angka Asymp. Sig. $(0,568)>0,05$, sedangkan data posttest kemampuan berpikir kreatif kelas kontol memiliki angka Asymp. Sig. $(0,878)>0,05$. Sehingga diputuskan data pretest-posttest kemampuan berpikir kreatif kedua kelas penelitian terdistribusi normal. Hasil uji homogenitas data pretestposttest kedua kelas penelitian dapat dilihat pada tabel 5.

Tabel 5. Hasil Uji Homogenitas

\begin{tabular}{ccccc}
\hline \multicolumn{5}{c}{ Test of Homogeneity of Variances } \\
\hline & Levene Statistic & df1 & df2 & Sig. \\
\hline Pretest & 0,103 & 1 & 34 & 0,751 \\
Posttest & 0,014 & 1 & 34 & 0,906 \\
\hline
\end{tabular}

Tabel 5 menunjukkan data pretest kemampuan berpikir kreatif kedua kelas penelitian memiliki angka Sig. $(0,751)>$ 0,05. Sedangkan, data posttest kemampuan berpikir kreatif kedua kelas penelitian memiliki angka Sig. $(0,906)>0,05$. Sehingga, diputuskan data pretest -posttest kemampuan berpikir kreatif kedua kelas penelitian homogen. Uji hipotesis menggunakan Mann-Whitney Test dengan tingkat kepercayaan 95\% $(\alpha=0,050)$. Uji hipotesis berbantuan program SPSS 20 for windows. Hasil uji hipotesisi ditunjukkan pada tabel 6.

Tabel 6. Hasil Uji Mann-Whitney Test untuk Posttest Kemampuan Berpikir Kreatif

\begin{tabular}{cc}
\hline \multicolumn{2}{c}{ Test Statistics $^{\mathbf{a}}$} \\
\hline \multicolumn{3}{c}{ Kemampuan Berpikir Kreatif (Posttest) $^{-}$} & 121,000 \\
Mann-Whitney U & 292,000 \\
Wilcoxon W & $-1,307$ \\
Z & 0,191 \\
Asymp. Sig. (2-tailed) & $0,203^{\mathrm{b}}$ \\
\hline
\end{tabular}

Tabel 6 memperlihatkan produk uji hipotesis menggunakan Mann-Whitney Test, data posttest kemampuan berpikir kreatif pada kedua kelas penelitian memiliki nilai Asymp. Sig. (2-taild) 0,191>0,05, sehingga $\mathrm{H}_{0}$ diterima. Sehingga, diputuskan tidak terdapat perbedaan kemampuan berpikir kreatif yang signifikan antara kedua kelas penelitian.

Tabel 7. Hasil Uji N-Gain Skor Kemampuan Bepikir Kreatif

\begin{tabular}{lccc}
\hline & \multicolumn{3}{c}{ N-Gain } \\
\cline { 2 - 4 } & $\mathrm{x}_{\min }$ & $\mathrm{x}_{\max }$ & $\mathrm{X}_{\text {rata-rata }}$ \\
\hline Kelas Eksperimen & 0,16 & 0,54 & 0,3380 \\
Kelas Kontrol & 0,14 & 0,54 & 0,3317 \\
\hline
\end{tabular}

Tabel 7 memperlihatkan produk pengujian N-Gain skor, data skor gain kemampuan berpikir kreatif kelas eksperimen sebesar 0,3380 dengan kategori sedang, sedangkan data skor gain kemampuan berpikir kreatif kelas kontrol sebesar 0,3317 dengan kategori sedang. Sehingga, diputuskan skor gain kemampuan berpikir kreatif kelas eksperimen dan kelas kontrol tidak berbeda. Gambar 2 memperlihatkan skor gain kedua kelas penelitian. 


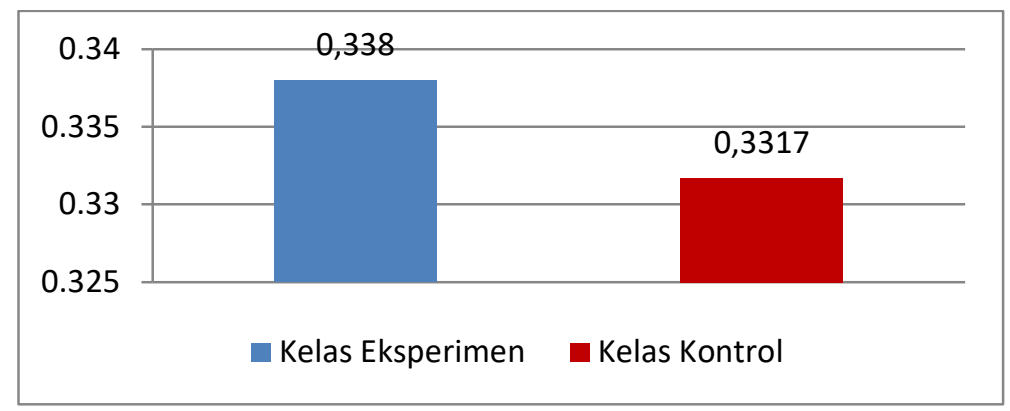

Gambar 2. Skor Gain Kemampuan Berpikir Kreatif

Berdasarkan gambar 2 dapat dilihat bahwa kedua kelas memiliki selisih yang sangat kecil. Skor gair kemampuan berpikir kreatif kedua kelas penelitian berada pada kategori sedang. Perbedaan skor gain kemampuan berpikir kreatif antara kelas eksperimen dan kelas kontrol diketahui dengan uji Mann-Whitney Test.

Tabel 8. Hasil Uji Mann-Whitney Test untuk N-Gain Skor

\begin{tabular}{cc}
\hline & \\
\hline & Test Statistics $^{\mathbf{a}}$ \\
\hline Mann-Whitney U & NGain_Score \\
Wilcoxon W & 159,500 \\
Z & 330,500 \\
Asymp. Sig. (2-tailed) & $-0,079$ \\
Exact Sig. [2*(1-tailed Sig.)] & 0,937 \\
\end{tabular}

Tabel 8 memperlihatkan hasil uji Mann-Whitney-Test untuk N-Gain skor, skor gain kemampuan berpikir kreatif pada kedua kelas penelitian memiliki nilai Asymp. Sig. (2-tailed) 0,937 >0,05. Sehingga, diputuskan tidak terdapat perbedaan skor gain kemampuan berpikir kreatif yang signifikan antara kelas eksperimen dan kelas kontrol.

\section{PEMBAHASAN}

Berdasarkan uji hipotesis dengan Mann-Whitney Test memiliki Asymp. Sig. (2-tailed) 0,191 > 0,05, menunjukkan tidak terdapat perbedaan kemampuan berpikir kreatif mahasiswa yang signifikan antara kedua kelas penelitian. Sehingga, disimpulkan kelas eksperimen yang diajarkan dengan model CBL tidak berpengaruh efektif terhadap kemampuan berpikir kreatif mahasiswa dibandingkan kelas kontrol yang diajarkan dengan model PBL. Model CBL tidak berpengaruh efektif terhadap kemampuan berpikir kreatif dikarenakan beberapa alasan berikut.

Alasan pertama, pelaksanaan pembelajaran kimia lingkungan belum sepenuhnya mempertimbangkan peningkatan keterampilan abad-21. Pelaksanaan pembelajaran menggunakan model CBL untuk meningkatkan keterampilan-keterampilan abad-21 harus memehuni beberapa unsur pertimbangan, meliputi pengajar yang berpengalaman, mahasiswa yang termotivasi, ketersediaan alat, dan bahan praktik, serta ketersediaan teknologi dan konektivitas internet (Kuswadi \& Nuh, 2016). Pelaksanaan pembelajaran harus memenuhi unsur pertimbangan tersebut, agar mahasiswa dapat melatih keterampilanketerampilan abad-21, meliputi inovasi, kreativitas, dan berpikir kritis.

Pengajar yang kurang berpengalaman akan menyebabkan masalah yang diselidiki oleh mahasiswa tidak mencapai kedalaman teknis yang diperlukan (Rådberg et al., 2018). Masalah yang kurang mendalam akan menyebabkan mahasiswa lebih mudah untuk memberikan solusi terhadap tantangan, dimana mahasiswa tidak mampu melatih kemampuan berpikir dengan baik. Dalam pelaksanaan pembelajaran kimia lingkungan pengajar telah memenuhi standar kelayakan dengan memahami tahapan model CBL. Hasil penelitian mengungkapkan bahwa kegiatan pembelajaran sudah dilakukan berdasarkan rencana pelaksanaan pembelajaran, walaupun belum maksimal.

Keterlibatan mahasiswa selama pembelajaran memiliki korelasi positif dengan keberhasilannya dalam memperoleh pengetahuan (Kuswadi \& Nuh, 2016). Jika mahasiswa kurang termotivasi, maka akan menyebabkan keterlibatan mereka dalam tahapan-tahapan pembelajaran menjadi rendah (Shuptrine, 2013). Kurangnya motivasi instrinsik akan membuat mahasiswa menjadi tidak fokus mengikuti tahapan-tahapan pembelajaran yang membutuhkan kemampuan berpikir tingkat tinggi. Dalam pelaksanaan pembelajaran kimia lingkungan mahasiswa kurang termotivasi dalam melakukan tahapan-tahapan pembelajaran. Hasil penelitian menunjukkan bahwa keterlibatan sebagian mahasiswa pada tahapan-tahapan pembelajaran masih rendah. 
Penggunaan alat dan bahan praktik dalam pembelajaran berbasis tantangan (CBL) sangat penting untuk membantu pekerjaan mahasiswa untuk menyelesaikan tantangan mereka (Apple Inc, 2010; Nichols et al., 2016). Penggunaan alat dan bahan praktik dalam kegiatan penyelidikan (praktikum) akan medorong mahasiswa menjadi ilmuan yang terampilan, serta membantu mahasiswa mengembangkan inovasi dan kreativitas mereka. Namun, dalam pelaksanaan pembelajaran kimia lingkungan terdapat keterbatasan alat dan bahan praktik, dimana kekurangan alat dan bahan praktik terjadi pada proyek pencemaran air, pencemran tanah, dan pencemaran udara. Sehingga, pengajar mendesain kegiatan penyelidikan (praktikum) yang lebih konstektual.

Penggunaan teknologi dan konektivitas internet dalam pembelajaran berbasis tantangan (CBL) sangat penting untuk memberikan ruang bagi mahasiswa dalam menemukan informasi dan memfasilitasi presentasinya (Tajuddin \& Jailani, 2013). Penggunaan teknologi dan konektivitas internet akan mendorong mahasiswa untuk berkomunikasi dan berinteraksi secara bebas (Cheng, 2016), membantu mahasiswa untuk berhubungan secara kolaboratif dengan masyarakat luar (Kuswadi \& Nuh, 2016), serta membantu mahasiswa untuk melakukan perubahan (Cruger, 2017). Namun, dalam pelaksanaan pembelajaran kimia lingkungan terdapat keterbatasan sarana dan prasarana, dimana penggunaan teknologi dan konektivitas internet belum memadai. Sehingga, mahasiswa masih bergantung dengan media sosial (WhatsApp) dan konektivitas internet sendiri.

Alasan kedua, keterbatasan waktu pembelajaran. Pembelajaran berbasis tantangan (CBL) membutuhkan banyak waktu, karena kegiatan pembelajaran juga berlangsung diluar kelas (Apple Inc, 2010; Cheng, 2016; Swiden, 2013). Jika mahasiswa memiliki banyak waktu untuk berinteraksi dengan aktor di lingkungan masyarakat, maka akan membantu mereka menjadi pemikir yang baik (Rådberg et al., 2018). Lebih banyak waktu yang dialokasikan untuk pembelajaran akan menjadikan mahasiswa sebagai pemikir yang berbeda dan kreatif (Santos et al., 2013). Namun, dalam pelaksanaan pembelajaran kimia lingkungan masih memiliki waktu yang terbatas, dimana pengajar hanya bisa membagi waktu 3 kali pertemuan untuk masingmasing pokok materi pencemaran lingkungan. Sehingga, waktu yang digunakan mahasiswa untuk mencari informasi di lingkungan masyarakat sangat sedikit.

Beberapa pertimbangan tersebut dalam pelaksanaan pembalajaran kimia lingkungan belum terpenuhi, meliputi; mahasiswa yang termotivasi, ketersediaan alat dan bahan praktik, serta ketersediaan teknologi dan konektivitas internet. Jika pertimbangan-pertimbangan ini terpenuhi saat pelaksanaan pembelajaran kimia lingkungan, maka kemungkinan kemampuan berpikir kreatif mahasiswa akan meningkat dari sebelumnya. Kemampuan berpikir kreatif akan meningkat apabila mahasiswa mempunyai kemauan untuk berkembang, memiliki fasilitas dan dukungan untuk menyelesaikan tantangan, serta melakukan kegiatan-kegiatan pembelajaran secara maksimal untuk mencapai tujuan.

Hasil penelitian sebelumnya menunjukkan model CBL efektif menumbuhkan kemampuan berpikir kreatif, tetapi tidak semua pembelajar memiliki kemampuan yang baik. Nufus, Duskri, \& Bahrun (2018), menyatakan bahwa model CBL mengorientasikan pembelajar agar berpikir kreatif, memiliki kepercayaan diri untuk memecahkan masalah, tetapi beberapa pembelajar masih berkemampuan rendah. Gaskins et al., (2015), menyatakan bahwa model CBL menawarkan potensi dalam membantu mahasiswa menjadi pemikir yang efektif dan fleksibel, dimana mahasiswa dapat menggunakan pengetahuan yang diperoleh untuk mengambil tindakan, namun penelitian yang cermat masih diperlukan untuk memahami apa dan bagaimana potensi ini dapat direalisasikan.

Hasil penelitian sebelumnya mengungkapkan bahwa model CBL yang diterapkan menggunakan teknologi abad-21 dan konektivitas internet dapat meningkatkan keterampilan mahasiswa dengan baik. Santos et al. (2013), menyatakan bahwa model CBL berbasis proses srum merupakan strategi yang efektif bagi mahasiswa sarjana untuk belajar dalam waktu singkat mengembangkan aplikasi seluler di lingkungan belajar yang kaya teknologi. Yoosomboon \& Wannapiroon (2015), menyatakan bahwa model CBL berbasis teknologi cloud dan media sosial dapat meningkatkan keterampilan menajemen informasi para ahli desain pembelajaran. Marin et al. (2013), mengemukakan bahwa model CBL yang dirancang dengan teknologi pembelajaran seluler iPad dapat menjadikan mahasiswa berbagi pengalaman dan wawasan mereka masing-masing. Selain itu, hasil penelitian sebelumnya juga menjelaskan model CBL juga membutuhkan waktu yang panjang. Cheng (2016), mengungkapkan bahwa proyek tersebut mungkin menuntut siswa untuk menyelesaikannya dalam satu semester, dimana pengajar harus berhati-hati dalam membimbing mahasiswa untuk menetapkan tantangan realistis dari ide besar mereka. Cheung et al. (2011), menjelaskan bahwa peningkatan dalam pembelajaran berbasis tantangan membutuhkan sumber daya dukungan tambahan dan memerlukan pertemuan pada waktu yang tidak teratur. Berdasarkan uji N-Gain skor dengan Mann-Whitney Test memiliki Asymp. Sig. (2tailed) 0,937 > 0,05, menunjukkan tidak terdapat perbedaan skor gain yang signifikan antara kedua kelas penelitian. Sehingga, disimpulkan kenaikkan kemampuan berpikir kreatif antara kedua kelas penelitian setara.

Peningkatan kemampuan berpikir kreatif yang sama antara kelas kedua kelas penelitian, karena kedua model pembelajaran yang diterapkan tersebut mengintegrasikan mahasiswa untuk menghasilkan bermacam solusi terhadap masalah lingkungan. Model CBL dan model PBL menyajikan masalah dunia nyata yang realistis, dimana mahasiswa memulai mengidentifikasi masalah, melakukan kegiatan penyelidikan, mencari sumber yang relevan, menentukan solusi, dan mempresentasikan solusi sebagai hasil karya. Mahasiswa dalam kegiatan pembelajaran dapat mengemukakan ide-ide baru, menyempurkan ide-ide sebelumnya, dan menilai ide-ide tersebut untuk dijadikan solusi penyelesaian masalah atau tantangan. 
Hasil penelitian sebelumnya oleh Suwono, Saefi, \& Susilo (2019), menunjukkan bahwa model CBL dan model PBL memiliki efek yang sama, tetapi lebih efektif dalam meningkatkan literasi ilmiah mahasiswa dibandingkan dengan DiskusiPresentasi, karena proses pembelajaran dari model CBL dan model PBL melibatkan inkuiri sebagai kerangka kerja utama. Suwono, Saefi, \& Susilo (2019), menjelaskan bahwa proses pembelajaran model CBL dan model PBL dapat membantu meningkatkan literasi sains mahasiswa karena bukan hanya memusatkan pada penerimaan pengetahuan, tetapi pemecahan masalah kontekstual dan nyata melalui penyelidikan. Jadi, secara garis besar, model CBL dan model PBL dapat memberdayakan mahasiswa untuk melatih kemampuan-kemampuan berpikir mahasiswa.

\section{SIMPULAN}

Berdasarkan semua kegiatan penelitian, maka dapar disimpulkan bahwa pengaruh penggunaan model Challenge Based Learning (CBL) lebih baik dibandingkan model Problem Based Learning (PBL) dalam meningkatkan kemampuan berpikir kreatif mahasiswa, walaupun secara statistik tidak ada perbedaan skor gain yang signifikan.

Pengajar dalam menerapkan model Challenge Based Learning (CBL) untuk menumbuhkan kemampuan berpikir harus mempertimbangkan unsur-unsur, meliputi pengajar yang berpengalaman, mahasiswa yang termotivasi, ketersediaan alat dan bahan praktik, serta ketersediaan teknologi dan konektivitas internet. Selain itu, pengajar perlu menyediakan lebih banyak waktu bagi mahasiswa untuk berkomunikasi dan berinteraksi di lingkungan masyarakat.

\section{DAFTAR RUJUKAN}

Apple Inc. (2010). Challenge Based Learning: A Classroom Guide. New York: Apple Inc.

Avellar, I. G. J. De, Cotta, T. A. P. G., \& Neder, Amarilis, D. V. F. (2012). Using Artificial Soil and Dry-Column Flash Chromatography To Simulate Organic Substance Leaching Process: A Colorful Environmental Chemistry Experiment. Journal of Chemical Education, 89(2), 248-253.

Baloian, N., Breuer, H., Hoeksema, K., Hoppe, U., \& Milrad, M. (2004). Implementing the Challenge Based Learning in Classroom Scenarios. Proceedings of the Symposium on Advanced Technologies in Education., 1-4.

Cheng, W. L. S. (2016). Application of Challenge-Based Learning in Nursing Education. Nurse Education Today, 44(2016), 130-135.

Cheung, R. S., Cohen, J. P., Lo, H. Z., \& Elia, F. (2011). Challenge Based Learning in Cybersecurity Education. Proceedings of The International Conference on Security and Menagement, (2011), 1-6.

Cruger, K. M. (2017). Applying Challenge-Based Learning in the (feminist) Communication Classroom : Positioning Students as Knowledgeable Change Agents. Communication Teacher, 32(2), 87-101.

Davis, E. J., Pauls, S., \& Dick, J. (2016). Project-Based Learning in Undergraduate Environmental Chemistry Laboratory: Using EPA Methods To Guide Student Method Development for Pesticide Quantitation. Journal of Chemical Education, 94(4), 451-457.

Fitriani, N. (2018). Pengaruh Model Challenge Based Learning terhadap Keterampilan Kolaboratif, Memecahkan Masalah, dan Kreativitas Ilmiah Mahasiswa S1 Jurusan Biologi. Tesis tidak diterbitkan. Universitas Negeri Malang, Malang.

Gaskins, W. B., Johnson, J., Maltbie, C., \& Kukreti, A. R. (2015). Changing the Learning Environment in the College of Engineering and Applied Science Using Challenge Based Learning. International Journal Education and Practice, 5(1), 33-41.

Günter, T., Akkuzu, N., \& Alpat, Ş. (2017). Understanding 'green chemistry' and 'sustainability': An Example of ProblemBased Learning (PBL). Research in Science \& Technological Education, 35(4), 500-520.

Jansson, S., Soderstrom, H., Andersson, P. L., \& Nording, M. L. (2015). Implementation of Problem-Based Learning in Environmental Chemistry. Journal of Chemical Education, 92(12), 2080-2086.

Johnson, L., \& Adams, S. (2011). Challenge Based Learning: The Report From the Implementation Project. Austin, Texas: The New Media Consortium.

Johnson, L. F., Smith, R. S., Smythe, J. T., \& Varon, R. K. (2009). Challenge-Based Learning: An Approach for Our Time. Austin, Texas: The New Media Consortium.

Jou, M., Hung, C.-K., \& Lai, S.-H. (2010). Application of Challenge Based Learning Approaches in Robotics Education. Inernational Journal Technologi Enggener in Education, 7(2), 17-20.

Kuswadi, S., \& Nuh, M. (2016). Effective Intelligent Control Teaching Environment Using Challenge Based Learning. International Symposium on Electronics and Smart Devices, (November 2016), 35-40.

Lasker, G. A., \& Brush, E. J. (2019). Integrating Social and Environmental Justice into the Chemistry Classroom : A Chemist's Toolbox. Green Chemistry Letters and Reviews, 12(2), 168-177.

Manahan, E. S. (2010). Enviromental Chemistry: 9th ed. USA: CRC Press.

Marin, C., Hargis, J., \& Cavanaugh, C. (2013). iPAD Learning Ecosystem : Developing Challenge-Based Learning using Design Thinking. Turkish Online Journal of Distance Education, 14(2), 22-34.

Nichols, M., Cator, K., \& Marco, T. (2016). Challenge Based Learning Guide. Redwood City, CA: Digital Promise.

Nufus, H., Duskri, M., \& Bahrun. (2018). Mathematical Creative Thinking and Student Self-Confidence in the Challenge-Based Learning Approach. Journal of Research Advances in Mathematics Education, 3(2), 57-68. 
O’Mahony, T. K., Vye, N. J., Bransford, J. D., Sanders, E. A., Stevens, R., Stephens, R. D., ... Soleiman, M. K. (2012). A Comparison of Lecture-Based and Challenge-Based Learning in a Workplace Setting: Course Designs, Patterns of Interactivity, and Learning Outcomes. Journal of the Learning Sciences, 21(1), 182-206.

Pellegrin, L., Chassery, L., Bonnardel, N., Tong, C., Santi, V. P. De, Taxier, G., \& Chaudet, H. (2019). Using Torrance Creative Thinking Criteria to Describe Complex Decision Making During an Outbreak Management by Public Health Experts. IEA, 3(2019), 50-59.

Rådberg, K. K., Lundqvist, U., Malmqvist, J., \& Hagvall, O. (2018). From CDIO to challenge-based learning experiences expanding student learning as well as societal impact?. European Journal of Engineering Education, (2018), 1-16.

Ryu, M., Nardo, J. E., Yang, M., \& Wu, M. (2018). An Examination of Preservice Elementary Teachers' Representations About Chemistry in An Intertextuality- and Modeling-Based Course. Chemistry Education Research and Practice, 19, 681-693.

Saefi, M., Suwono, H., \& Susilo, H. (2017). Studi Komparatif Tiga Strategi Berpikir Kriris Mahasiswa Biologi. Jurnal Pendidikan: Teori, Penelitian, dan Pengembangan, 2(5), 637-645.

Salta, K., Gekos, M., Petsimeri, I., \& Koulougliotis, D. (2012). Discovering Factors that Influence The Decision to Pursue A Chemistry-Related Career: A Comparative Analysis of The Experiences of Non Scientist Adults and Chemistry Teachers in Greece. Chemistry Education Research and Practice, 13, 437-446.

Santos, A. R., Sales, A., Fernandes, P., \& Nichols, M. (2015). Combining Challenge-Based Learning and Scrum Framework for Mobile Application Development. ITiCSE'15, (July 2015), 189-194.

Savian, H., \& Talanquer, V. (2014). Rethinking Chemistry : A Learning Progression on Chemical Thinking. Chemistry Education Research and Practice, 15, 10-23.

Shuptrine, C. (2013). Improving College and Career Readiness Through Challenge-Based Learning. Contemporary Issues In Education Research-Second Quarter 2013, 6(2), 181-188.

Suwono, H., Saefi, M., \& Susilo, H. (2019). Challenge Based Learning to Improve Scientific Literacy of Undergraduate Biology Students. International Conference for Science Educators and Teachers, (March 2018), 1-7.

Swiden, C. L. (2013). Effects Challenge Based Learning on Student Motivation and Achievement. Bozeman, Montana: Montana State University.

Tajuddin, S. M., \& Jailani, A. (2013). Challenge Based Learning in Students for Vocational Skills. International Journal of Independent Research and Studies, 2(2), 89-94.

Yang, Z., Zhou, Y., Chung, J. W. Y., Tang, Q., Jiang, L., \& Wong, T. K. S. (2018). Challenge Based Learning Nurtures Creative Thinking: An Evaluative Study. Nurse Education Today, 71(2018), 40-47.

Yoosomboon, S., \& Wannapiroon, P. (2015). Development of a Challenge Based Learning Model Via Cloud Technology and Social Media for Enhancing Information Management Skills. Procedia - Social and Behavioral Sciences, 174(2015), 2102-2107. 